\title{
GENEALOGÍA DE UNA FRACTURA: PLURINACIONALISMO Y MOVIMIENTOS SOCIALES EN LA BOLIVIA DE MORALES
}

\section{Genealogy of a fracture: plurinationalism and social movements in Morales'Bolivia \\ Genealogia de uma fratura: plurinacionalismo e movimentos sociais na Bolívia de Morales}

\author{
Camilla De Ambroggi \\ Universidad de Bolonia, Italia \\ Informações do artigo \\ Recebido em 21/06/2020 \\ Aceito em 21/08/2020
}

doi>: https://doi.org/10.25247/2447-861X.2020.n250.p305-338

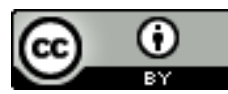

Esta obra está licenciada com uma Licença Creative Commons Atribuição 4.0 Internacional.

\section{Como ser citado (modelo ABNT)}

AMBROGGI, Camilla De. Genealogía de una fractura: plurinacionalismo y movimientos sociales en la Bolivia de Morales. Cadernos do CEAS: Revista Crítica de Humanidades. Salvador/Recife, v. 45, n. 250, p. 305-338, maio/ago. 2020. DOI: https://doi.org/10.25247/2447861X.2020.n250.p305-338

\begin{abstract}
Resumen
El artículo pretende dar cuenta de la genealogía de las protestas explotadas en Bolivia en octubre 2019 en respuesta a la cuarta victoria electoral consecutiva del MAS con Evo Morales como presidente. Para lograr este objetivo se analizan las trasformaciones ocurridas durante el gobierno del MAS en la sociedad boliviana en términos de participación política y ampliación de espacios de poder. En específico, rastreando las formas en la que se reconfiguraron las relaciones entre los varios sectores populares en los catorce años de gobierno masista, el artículo intenta sacar a la luz las fracturas y las tensiones existentes bajo el intento del MAS de volverse una figura institucionalizada de mediación entre los movimientos sociales y la élite terrateniente de los departamentos orientales. Por fin, se argumenta que el motivo de la violenta derrota de Evo Morales en primavera 2019 fue la explosión de estas fracturas debida a la imposibilidad de representar el abigarramiento de la sociedad boliviana bajo el paradigma del Estado Plurinacional impulsado por el MAS.
\end{abstract}

Palabras Clave: Movimiento al Socialismo (MAS). Bolivia. Plurinacional. Gobiernos progresistas. Movimientos indígenas.

\section{Abstract}

The article aims to give an account of the genealogy of the protests exploited in Bolivia in October 2019 as a response to the fourth consecutive electoral victory of MAS with Evo Morales as president. To achieve this objective, the article analyzes the transformations that occurred during the MAS government in Bolivian society in terms of political participation and expansion of spaces of power. Specifically, by tracing the ways in which relations between the various popular sectors have been reconfigured during the fourteen years of the masista government, the article attempts to bring to light the fractures and tensions existing under the MAS' attempt to become an institutionalized figure of mediation between the social movements and the landowning elite of the eastern departments. Finally, it is argued that the reason for the violent defeat of Evo Morales in Autumn 2019 was the explosion of these fractures due to the impossibility of representing the abigarrada nature of Bolivian society under the Plurinational State paradigm promoted by the MAS.

Keywords: Movement towards Socialism (MAS). Bolivia. Plurinational.

Progressive governments. Indigenous movements.

Resumo

O artigo pretende dar conta da genealogia dos protestos explodidos na Bolívia em Outubro de 2019, como resposta à quarta vitória eleitoral consecutiva do MAS com Evo Morales como presidente. Para alcançar este objectivo, o artigo analisa as transformações ocorridas durante o governo do MAS na sociedade boliviana em termos de participação política e de expansão dos espaços de poder. Especificamente, ao traçar as formas como as relações entre os vários sectores populares foram reconfiguradas durante os catorze anos do governo masista, o artigo tenta trazer à luz do dia as fracturas e tensões existentes sob a tentativa do MAS de se tornar uma figura institucionalizada de mediação entre os movimentos sociais e a elite latifundiária dos departamentos orientais. Finalmente, argumenta-se que a razão da derrota violenta de Evo Morales no Primavera de 2019 foi a explosão destas fracturas devido à impossibilidade de representar a natureza abigarrada da sociedade boliviana sob o paradigma do Estado Plurinacional promovido pelo MAS.

Palavras-chave: Movimento para o Socialismo (MAS). Bolívia. Plurinacional.

Governos progressistas. Movimentos indígenas. 


\section{Introducción}

El domingo 20 de octubre 2019, día de las elecciones presidenciales, Bolivia cayó en una crisis institucional sin precedentes que el 12 de noviembre marcó definitivamente el fin de la presidencia de Evo Morales y, junto a eso, el fin de uno de los gobiernos más sólidos de la historia del país, así como uno de los gobiernos progresistas latinoamericanos más longevo con sus catorce años consecutivos al poder. Las tres semanas que transcurrieron entre la victoria electoral del MAS (Movimiento Al Socialismo) con el binomio Morales - García Linera con un supuesto $46,85 \%$ de los votos y el abandono del país de los dos candidatos tras el "pedido" del General de las Fuerzas Armadas bolivianas Williams Kaliman Romero de que Morales renunciara al mandato presidencial, fueron cruzadas por masivas movilizaciones y levantamientos encabezados por heterogéneos sectores de la sociedad civil, tanto a favor cuanto contrarios al gobierno masista; estas protestas se transformaron en una verdadera guerra civil cuando, el 12 de noviembre, la presidencia fue asumida por la ex presidenta del Senado Jeanine Añez a través de una votación parlamentar en la cual fue prohibida la participación de los diputados del MAS.

La violencia y el alcance de las movilizaciones de esos días, junto con la importancia regional de un cambio de mando en un país que había sido un baluarte del "giro progresista" latinoamericano y en un momento histórico para América Latina que en esos meses se veía cruzada por masivas movilizaciones sociales, desencadenaron una pluralidad de lecturas e interpretaciones sobre los hechos bolivianos que al final convergieron en dos diferentes posturas: por un lado una visión que sostiene que Evo Morales ha sido víctima de un golpe de estado encabezado por la derecha ultraconservadora con el apoyo de Estados Unidos y, por otro lado, una interpretación que respalda la hipótesis, avalada también por un documento ambiguo de la Organización de los Estados Americanos (OEA) ${ }^{1}$, de que Morales ha cometido un fraude electoral y por eso fue justamente depuesto de su mando. La particularidad de esta polaridad es que la hipótesis de fraude electoral fue respaldada no simplemente por la derecha ultraconservadora y por la oligarquía agroindustrial del oriente boliviano, con el repentino ascenso político del empresario Fernando Camacho, sino también por muchos

\footnotetext{
${ }^{1}$ Disponible en http://www.oas.org/documents/spa/press/Informe-Auditoria-Bolivia-2019.pdf. Acceso el 10 jun. 2020.
} 
sectores de movimientos sociales, indígenas y sindicatos que en la primera década de los 2000 habían apoyado el gobierno del MAS.

Sin embargo, ambas interpretaciones - la del golpe de estado y la de la caída de un gobierno fraudulento y corrupto - de hecho, corren el riesgo de anular la heterogeneidad y el abigarramiento de sujetos y fuerzas que confluyeron en las movilizaciones de esos días. La postura que sostiene que en Bolivia hubo un golpe de estado, invisibiliza la multitud de campesinos, indígenas y sindicatos que también se unieron a las protestas que demandaban la renuncia de Morales. De la misma manera, esta postura no toma en cuenta la continuidad que existe no solo entre el gobierno de Morales y el nuevo gobierno de Añez, sino también la que existe entre los catorce años de socialismo comunitario promovido por el MAS y el periodo neoliberal anterior, cuando comenzó a reformarse el paradigma estatal en llave multicultural. Por otro lado, la postura que plantea la idea de que Morales cayó por sus errores y que el fraude electoral legitima el exilio del ex presidente, invisibiliza el racismo y el revanchismo antipopular desplegado por las fuerzas reaccionarias que descalificaron las movilizaciones y la política de los sectores indígenas y campesinos aliados al MAS como "bárbaras" y vandálicas, así como el intento de borrar el legado material y simbólico del gobierno del MAS. Además, con la legitimación del exilio de Morales, se acaba por legitimar el despliegue masivo de violencia perpetrado por la oposición conservadora tanto a nivel simbólico con los actos de quema de la wiphala y con sus discursos reaccionarios llenos de patriarcalismo y clasismo, como a nivel material con ataque a exponentes del gobierno y a sus militantes, también con el respaldo del nuevo gobierno que con el Decreto Supremo 4078 autorizó las Fuerzas Armadas a reprimir las protestas eximiéndolas de responsabilidad penal.

El intento de este articulo entonces no es tanto de arrojar luz sobre las opuestas interpretaciones del octubre boliviano, sino lo de dar cuenta de lo que queda afuera de estas. De hecho, como señalaron Verónica Gago y Diego Sztulwark (2016), los análisis regionales sobre el llamado fin de ciclo de los gobiernos progresistas - y en este caso específico sobre el fin del gobierno de Morales - no pueden detenerse a una simple evaluación de las políticas estatales y gubernamentales sino que tienen que tener en cuenta "la pluralidad de dimensiones en las que se juegan tanto continuidades como discontinuidades que remiten a lógicas más profundas que las referidas por el sistema político" (GAGO, SZTULWARK, 2016, p. 607). 
Sin embargo, al mirar debajo de los hechos que llevaron a la caída de Morales, se observa la existencia de una tensión política que no puede reducirse a la dinámica institucional y que no puede sintetizarse sólo atribuyendo la responsabilidad de la violenta crisis política o del golpe a una u otra facción. Las protestas de primavera 2019 estuvieron animadas por un sujeto heterogéneo, difícil de encuadrar, que incluye una gran parte de los sectores populares-indígenas. En realidad, el mismo proceso que llevó a la elección de Evo Morales a la presidencia de Bolivia en 2005 con un impactante $54 \%$ de los votos, está hecho de una pluralidad de dimensiones, subjetividades y experiencias que no pueden ser consideradas como coincidentes con el gobierno del MAS y que hay que sacar a la luz para comprender las transformaciones de la sociedad boliviana durante el gobierno masista.

La victoria de Morales fue uno de los resultados del masivo ciclo de insurgencias nombrado por algunos autores el "ciclo rebelde" (LÓPEZ, MAKARAN, 2018; SALAZAR, 2015) - que al principio del nuevo milenio vio a miles de mujeres y hombres de diferentes sectores sociales luchar para un cambio estructural del modelo estatal boliviano. Este ciclo rebelde que tiene como momentos de mayor confluencia de fuerzas anti-sistémicas la Guerra del Agua (2000) y las dos Guerras del Gas (2003 y 2005) - fue animado por una extraordinaria pluralidad de sujetos que antes habían sido sistemáticamente excluidos del campo de la política, tanto que algunos autores y autoras (TAPIA, GUTIÉRREZ AGUILAR, PRADA, GARCÍA LINERA, 2000; 2002) señalaron como en este ciclo se vio la emergencia de una nueva forma de movilización popular, la "forma multitud". Ésta sería una forma de agrupación política y social capaz de articular diferentes estructuras y organizaciones autónomas, así como individuos "sueltos" en un bloque de acción colectivo donde modelos y prácticas de los movimientos de la izquierda tradicionales, como los sindicatos, se combinan con prácticas y discursos comunitarios y rurales, sin que ninguno de estos cree una hegemonía (LINERA, 2009b, p.381). Según estos autores, hablar de forma multitud daría cuenta de la modalidad especifica en la que las demandas de la clase obrera boliviana fueron reformuladas en los años 2000 teniendo en cuenta lo que el politólogo boliviano René Zavaleta Mercado (1986) llamó el carácter "abigarrado" de la sociedad boliviana, en el que coexisten de manera desigual y

\footnotetext{
2 Para más información sobre el desarrollo y las diferentes etapas de estos conflictos véase: Olivera (2004), Spronk (2007), Mamani Ramírez (2006), Webber (2011, p. 184-228).
} 
desarticulada varias formas de relaciones sociales y diferentes modos de producciones económicos que, aunque establezcan relaciones de dominación y distorsión una sobre otra, no logran uniformarse (GARCÍA LINERA ET AL. 2002; DUNKERLY 2007, p. 38-40; OLIVERA, LEWIS, 2004; TAPIA 2002).

Esta forma multitud tuvo una extraordinaria capacidad para reclamar nuevos espacios políticos, que le dio la posibilidad de hacer valer parte de sus demandas en el proceso constituyente abierto por Morales en 2006 para formular la nueva constitución de Bolivia. Para comprender tanto las continuidades como las discontinuidades entre el gobierno del MAS y los movimientos sociales que lo llevaron al poder es entonces necesario investigar los cambios estructurales generados por los varios sectores que componían la multitud en movimiento, sin caer en la trampa de uniformar la heterogeneidad de sujetos que la componen. Por lo contrario, hay que subrayar la forma en que esta pluralidad se articuló en las distintas fases del gobierno Morales, actuando un poder de veto (MEZZADRA, GAGO, 2017, p. 484), o sea una capacidad autónoma de negociar con el Estado, que sucedió en derrotar la legitimidad del consenso neoliberal de los años 80 y 90 y produjo una ampliación de la participación popular en los procesos de decisión del gobierno (POSTERO, 2017, p. 32).

\section{Más allá del Evismo}

En 2006, una vez en el poder, Evo Morales inició el llamado proceso de cambio, que se suponía iba a servir para activar las demandas surgidas en el ciclo de movilizaciones iniciado con la Guerra del Agua en el año 2000 y culminado en la segunda Guerra del Gas de octubre de 2005. El primer punto a cumplir era la realización de una Asamblea Constituyente y finalmente acabar con el predominio de lo que Zavaleta Mercado llamó el "poder de la casta señorial", o sea de la élite oligárquica de descendencia europea que implementó una forma de "Estado aparente" en Bolivia (ZAVALETA, 1986), ya que carece de una relación orgánica con la población sobre la que pretende gobernar y no tiene en cuenta la condición abigarrada (ZAVALETA, 1986) o multisocietal (TAPIA, 2002)3 del territorio boliviano.

3 Luis Tapia, en La condición multisocietal. Multiculturalidad, pluralismo y modernidad, retoma el concepto de abigarramiento elaborado por Zavaleta Mercado hablando de condición multisocietal, para dar cuenta de la carencia de un paradigma hegemónico en la sociedad boliviana. 
La demanda de una Asamblea Constituyente para refundar la estructura del Estado en clave plural tiene sin embargo una genealogía mucho más larga, que ya es indicativa de las discontinuidades entre los movimientos sociales y el MAS. Esta demanda fue avanzada en el marco de la gran Marcha por el Territorio y la Dignidad de 1990, convocada por la Central de Pueblos Indígenas del Beni (CPIB) para protestar en contra de las privatizaciones neoliberales de territorios y recursos indígenas implementadas por el gobierno de Víctor Paz Estenssoro (LOPEZ Y MAKARAN, 2018, p. 74). En la marcha de 600 km de Trinidad a La Paz, el CPIB logró movilizar también otros sectores de la sociedad, poniendo las bases para la articulación que daría vida a las insurgencias de los años 2000. De hecho, según Luis Tapia, fue en este momento que los movimientos indígenas se transformaron de movimientos sociales a "movimientos societales", es decir pasaron de ser movimientos que simplemente reclaman participación en la arena política y en el discurso del Estado, a ser movimientos capaces de cuestionar y reformar la estructura misma del Estado y su relación con la sociedad, promoviendo así una alternativa a la idea del Estado-nación neoliberal (TAPIA, 2008, p. 62).

Los primeros a sumarse a la Marcha fueron organizaciones indígenas como la CIDOB (Confederación de los Pueblos Indígenas del Oriente Boliviano) y la APG (Asamblea del Pueblo Guaraní), pero también sindicatos de mineros como la COB (Central Obrera Boliviana) y de campesinos como la CSUTCB (Confederación Sindical Única de Trabajadores Campesinos de Bolivia). La amplia movilización que la Marcha logró levantar fue un hito histórico para los movimientos bolivianos, porque dio el paso para reformular las demandas de clase de los sindicatos incluyendo también las de los indígenas y de las comunidades rurales de Bolivia. Hasta aquel momento la COB había sido la mayor estructura de coordinación de la clase obrera y campesina: ésta se formó en 1952 cuando, en el marco de la Revolución Nacional, empezó a surgir un proletariado minero en consecuencia de la industrialización y nacionalización de las minas llevado a cabo por el MNR (Movimiento Nacionalista Revolucionario) y a la consiguiente masiva migración de indígenas del campo a la ciudad en busca de trabajo (LÓPEZ Y MAKARAN, 2018, p. 54). Gracias también a la estrategia del MNR que preveía un control estatal del proceso productivo combinado con el potenciamiento de los sindicatos para ampliar la participación popular en este proceso económico, la COB se convirtió en la "vanguardia" de la clase obrera boliviana (WEBBER, 2011: 72). Sin embargo, la Revolución de 1952 llevó a integrar a los indígenas en una estructura sindicalista como trabajadores rurales y a suprimir la categoría "indio" 
sustituyéndola por la de campesino en un intento de convertir a la "anacrónica" mayoría indígena en una clase obrera moderna que pudiera sustituir y abolir el poder de la clase hacendaria (CANESSA, 2007, p. 200). Este liderazgo que la COB mantenía como estructura de coordinación de la clase obrera y campesina empezó a debilitarse cuando en 1979 surgió la CSUTCB como resultado de la lucha del movimiento katarista impulsado por intelectuales aymaras que, basándose en la ideología del indianismo desarrollada por Fausto Reinaga ${ }^{4}$, comenzaron a exigir el reconocimiento cultural y los derechos sobre la tierra y a reivindicar con su Manifiesto de Tiahuanacu de 1973 - la necesidad de articular la conciencia de clase dentro de una posición étnica (POSTERO, 2007, p. 42).

Sin embargo, fue solo en la Marcha por el Territorio y la Dignidad de 1990 que el rol de la COB como vanguardia de la clase obrera, que mantenía en una posición subalterna la componente campesina e indígena en su interior, empezó a debilitarse como resultado de la emergencia de las organizaciones indígenas de tierras bajas como la CIDOB y la APG. Éstas surgieron en los años 80 gracias también al trabajo de varias ONGs locales que patrocinaron reuniones entre distintos grupos indígenas que en tierras bajas estaban mayormente aislados y divididos respecto a los de la región andina a causa de la forma histórica en la que se dio la explotación y la dominación en tierras bajas desde la época colonial, cuando los primeros misioneros jesuitas promovieron el sistema de reducciones (KLEIN, 2011: 35, 45) ${ }^{5}$. Aunque el apoyo económico y técnico de las ONGs llevó muchos grupos indígenas a depender de esas para enfrentarse al Estado, en todo caso en la Marcha se demostró inequívocamente como la emergencia de los indígenas de tierras bajas fue necesaria para romper la estructura política de organización social heredada del nacionalismo revolucionario, basada en el sindicato, y para establecer nuevas formas de activismo político en las que los movimientos indígenas comenzaron a articular sus demandas en forma autónoma y en términos de derechos sobre la tierra.

\footnotetext{
4 Para una profundización de la ideología del indianismo ver: Hurtado (1986); Reinaga (1970).

5 A final del siglo XIX, la formación de latifundios y haciendas aumentaron la fragmentación de las comunidades sometiendo los indígenas de tierras bajas en un régimen de trabajo forzoso dentro del sistema de empatronamiento (MORELL I TORRA, 2013, p. 46) y las reformas neoliberales de los '80, con inversiones masivas para la industrialización del sector agrícola, llevaron a la expansión de la frontera agrícola en detrimento de los territorios indígenas y al enriquecimiento de la élite terrateniente de Santa Cruz (POSTERO, 2007, p. 47). Para profundizar las distintas trayectorias históricas que afectaron los indígenas de tierras bajas y que llevaron a la formación de la APG y la CIDOB ve: Albó (1990); Combès - Saignes, (1991); Cuarey, (2015).
} 
Esta marcha entonces logró conectar por primera vez las demandas de los indígenas de las tierras bajas con las de las tierras altas, que hasta aquel momento habían tenido dos trayectorias de politización diferentes (LÓPEZ Y MAKARAN, 2018, p. 75), así como las demandas indígenas con las de los mineros sindicalizados. Fue en este contexto que se puede rastrear el comienzo de la convergencia entre los varios sectores de la que fue denominada forma multitud (LINERA, 200gb). Estos sectores del campo popular, en septiembre de 2004, formaron el Pacto de Unidad ${ }^{6}$, un espacio de articulación política y alianza para avanzar demandas en el proceso de la Asamblea Constituyente (LÓPEZ Y MAKARAN, 2018, p. 90). El 5 de agosto de 2006, un día antes del inicio de la Asamblea Constituyente (AC), esta alianza presentó la Propuesta para la Nueva Constitución Política del Estado (PNCPE), que contenía los lineamientos de su visión para la nueva Constitución.

El principal objetivo de los firmantes del Pacto de Unidad era la refundación del Estado que debería garantizar la autodeterminación de las comunidades indígenas, una democracia plural y participativa y la erradicación de los legados coloniales que habían sustentado un régimen de exclusión, dominación y discriminación contra algunos sectores de la sociedad. Para alcanzar este objetivo, la PNCPE delineó tres estrategias diferentes: el reconocimiento de los pueblos indígenas como "naciones dentro de una nación" a través del paradigma del plurinacionalismo y de la reivindicación de sus derechos como sujetos colectivos; un nuevo sistema de redistribución de la tierra que debería garantizar la propiedad colectiva sobre los territorios ancestrales y el control de sus recursos; y, por último, una apertura en el proceso de toma de decisiones del Estado, que se habría logrado reconociendo los sistemas jurídicos indígenas y campesinos, así como su medicina, su educación, su lengua y su autoridad, en un plano de igualdad frente a los liberales "europeos". A su vez, todos estos objetivos debían alcanzarse mediante la descentralización del Estado y la puesta en marcha de formas autónomas de gobierno indígena (PNCPE, 2016).

6 Las organizaciones que componían el Pacto de Unidad eran: la Confederación Sindical Única de Trabajadores Campesinos de Bolivia (CSUTCB), la Confederación de Pueblos Indígenas de Bolivia (CIDOB), el Consejo Nacional de Ayllus y Markas del Qollasuyo (CONAMAQ), la Confederación Sindical de Colonizadores de Bolivia (CSCB), la Federación Nacional de Mujeres Campesinas de Bolivia-Bartolina Sisa (FNMCB-BS), la Coordinadora de Pueblos Étnicos de Santa Cruz (CPESC), el Movimiento Sin Tierra de Bolivia (MST), la Asamblea del Pueblo Guaraní (APG) y la Confederación de Pueblos Étnicos Moxeños del Beni (CPEMB). 
Sin duda, la elaboración del PNCPE representó un avance crucial para las organizaciones indígenas y campesinas que, en el contexto del ciclo rebelde y con su crítica a las políticas neoliberales y multiculturales, redefinieron su identidad como colectivo plural, a partir de la elaboración de experiencias históricas acumuladas de exclusión y opresión (TAPIA, 2014), y la asumieron como la posición adecuada para el desmantelamiento del colonialismo interno del Estado, como plantea el propio Preámbulo del PNCPE:

\begin{abstract}
Las naciones y pueblos indígenas originarios y campesinos hoy tienen el desafío de participar en la refundación de Bolivia, construyendo un nuevo país fundamentado en los pueblos como sujetos colectivos, hacia la construcción de un Estado Plurinacional, que trascienda el modelo de Estado liberal y monocultural cimentado en el ciudadano individual. [...] Entendemos que el Estado Plurinacional es un modelo de organización política para la descolonización de nuestras naciones y pueblos, reafirmando, recuperando y fortaleciendo nuestra autonomía territorial, para alcanzar la vida plena, para vivir bien, con una visión solidaria, [...] Nuestra decisión de construir el Estado Plurinacional basado en las autonomías indígenas, originarias y campesinas, debe ser entendida como un camino hacia nuestra autodeterminación como naciones y pueblos." (PNCPE, 2006, Preámbulo)
\end{abstract}

Queda entonces claro cómo los firmantes del Pacto mantuvieron un posicionamiento autónomo en respecto al gobierno de Morales, para traducir las luchas que venían haciendo desde años en un mandato para negociar cambios políticos y económicos y superar el paradigma neoliberal (GAGO Y MEZZADRA, 2017, p. 447). No obstante, el MAS, por medio de la Ley 3364 de 2006 que convocó a la AC (POSTERO, 2017, p. 49), estableció la posibilidad de participar en la AC sólo por medio de partidos políticos, agrupaciones ciudadanas o pueblos indígenas reconocidos por la Corte Electoral, intentando así incorporar sujetos y movimientos sin este reconocimiento en el MAS y negando a varios miembros de las organizaciones sociales, indígenas y campesinas, que en realidad eran los principales impulsores de la AC, a participar directamente en ella (LÓPEZ Y MAKARAN, 2018, p. 94). De esta manera, el MAS puso las bases para volverse en el único representante de los varios sectores de movimientos sociales, indígenas y sindicatos que llevaron adelante el proceso de refundación del Estado, homogeneizando e institucionalizando la pluralidad de sujetos y dimensiones que animaban la forma multitud.

Por otra parte, el MAS tuvo que enfrentarse a otra fuerte corriente dentro de la AC: cuando el 2 de julio de 2006 se celebraron las elecciones de los miembros de la Asamblea Constituyente, el Partido Podemos junto con el Comité Cívico de Santa Cruz, que representaban el interés de la oligarquía de los departamentos de las tierras bajas, obtuvo 60 escaños. Esta élite terrateniente - que hacía negocios en el mercado internacional vendiendo 
soja, girasol, sorgo, ganado y gas natural - era el principal propulsor económico de Bolivia y, por consiguiente, una fuerza política influyente que se opuso firmemente a las demandas de los indígenas y campesinos (POSTERO, 2017, p. 48); por el contrario, abogaron por la continuación del proyecto neoliberal de descentralización del Estado empezado por Sánchez de Lozada con la Ley de Participación Popular (LPP) en $1994^{7}$ y con lo que se llamó "multiculturalismo neoliberal" (HALE, 2005; POSTERO, 2007; WEBBER, 2011), que es una forma de reconocimiento cultural de los pueblos indígenas y los grupos minoritarios que, al permitirles entrar en el espacio político del Estado como sujetos de derecho, también regula su vida económica y social, creando entonces una relación estricta entre los derechos culturales y las reformas económico-políticas neoliberales. El intento de la llamada Media Luna ${ }^{8}$ era entonces lo de garantizar la autonomía a los departamentos, pero no a las comunidades indígenas. El modelo constitucional que promovían se basaba en el Estado autonómico español, tal como se instituyó en la Constitución de 1978 (NOGUERA, 2008, p. 153). En efecto, exigían un aparato administrativo en el que los departamentos tuvieran poder para legislar y tomar decisiones sobre proyectos de desarrollo, a fin de asegurar sus ingresos económicos y su poder político; en consecuencia, se plantearon en una firme oposición a la redistribución de la tierra y al proyecto de nacionalización querido por el Pacto de Unidad, que habría amenazado su interés de clase como hacenderos.

En fin, el Pacto de Unidad y la élite de la Media Luna fueron las dos principales fuerzas dentro de la AC con las cuales el MAS tuve que llegar a un acuerdo y hacer concesiones, ya que sus poderes de veto afectaron no sólo al proceso constitucional, que estuvo paralizado durante meses, sino a todo el país, donde las revueltas populares volvieron a estallar en los dos frentes. Las movilizaciones indígenas se extendieron por toda Bolivia exigiendo una mayor participación en la AC y pidiendo al MAS que persiguiera fielmente sus intereses, mientras que, en Santa Cruz, en septiembre de 2008, un grupo de activistas del Comité tomó

7 La LLP, promovida por el gobierno de Lozada como una ley capaz de ampliar la participación de las comunidades indígenas en la vida política y jurídica de la nación reconociendo su condición jurídica, fue en realidad impulsada por las élites de los departamentos orientales que presionaron por una mayor independencia del Estado central, en línea con la reestructuración política neoliberal (POSTERO, 2007: 53). De hecho, la Ley otorgó derechos, obligaciones, recursos económicos y facultades para ejercer el control social en materia de educación, salud, cultura o deportes no directamente a las comunidades indígenas que lo requerían sino a los Gobiernos Municipales en los que se encontraban (LPP: artículos 2,3).

8 Los departamentos orientales de Tarija, Santa Cruz, Beni y Pando son llamados la "Media Luna" por su disposición geográfica en el territorio boliviano que parece una media luna. 
el control de los edificios del Estado y declaró la autonomía del departamento $(\mathrm{SCHAVELZON}, 2012)^{9}$. En este contexto de tensión y estancamiento, que duró más de dos años, Evo Morales, con su capacidad de establecer alianzas tácticas y estratégicas en cada momento (PETRAS, 2005: 199), terminó siendo el árbitro entre las dos facciones, tratando de mediar sus divergencias. Después de una serie de negociaciones sobre los principales temas en debate, el MAS cumplió con algunas de las peticiones del Pacto de Unidad, como la implementación de formas de gobiernos indígenas autónomos (AIOC: Autonomía Indígena Originaria Campesina), mientras que al mismo tiempo hizo concesiones sustanciales a los departamentos de las tierras bajas, en relación con la autonomía y la administración de sus ingresos (POSTERO, 2017: 51). Al final, el texto definitivo fue aprobado por los dos tercios de los delegados y el 25 de enero de 2009 se celebró el referéndum en el que la población, con una participación del 90,24\%, aprobó la Constitución por un margen del 60\% (LÓPEZ Y MAKARÁN, 2018, p. 96). El 7 de febrero de 2009, en la ciudad símbolo de la revuelta de los años 2000, El Alto, se promulgó finalmente la nueva y debatida Constitución del refundado Estado Plurinacional de Bolivia (CPE: Constitución Política del Estado).

Sin embargo, ya que la nueva Constitución incorpora algunas reivindicaciones tanto de la élite terrateniente como de los movimientos sociales, resultó una "Constitución abierta" (SCHAVELZON, 2012, p. 415), que contiene una tensión entre varias definiciones estructurales, que dan lugar a ambigüedades, contradicciones o "espacios de indefinición estratégicos", que a su vez conducen a la coexistencia de horizontes liberales e indígenas, inspirados en diversos proyectos políticos (SCHAVELZON, 2012, p. 416). En efecto, por un lado, aunque los miembros de las organizaciones indígenas y campesinas no pudieron participar directamente en la AC, su capacidad de articular eficientemente sus intereses y demandas y de hacer valer su poder de veto también en las calles con protestas y con diferentes practicas sociales, los llevó a ser una fuerza política fuerte dentro de la AC, incluso bajo la representación del MAS, y a seguir avanzando sus demandas más allá del contexto constitucional (GARCÉS, 2013, p. 32). Por otro lado, la pérdida de poder que las élites regionales temían como resultado del intento del Pacto de Unidad de transformar la

\footnotetext{
9 Para más detalles sobre las revueltas llevadas a cabo durante los primeros meses de la AC ver: Schavelzon
} (2012). 
estructura de las clases rurales bolivianas y de la distribución de tierras, las llevó a demandar, y obtener, la continuación del paradigma de descentralización neoliberal con la autonomía de los departamentos orientales de Santa Cruz, Tarija, Beni y Pando. De esta manera la Media Luna puso las bases por una alianza con el Estado funcional a la exportación en el mercado mundial de productos agroalimentarios (KAY, VERGARA-CAMUS, 2018 p. 190). Es en este contexto que ya empezaron a emerger las fracturas existentes bajo el longevo gobierno del MAS y que están a la base de las dinámicas que lo derrotaron en 2019: la salida pactada por el MAS al interior del proceso constituyente, fomentó líneas de divisiones que al final pueden explicar tanto el rápido ascenso del Comité Cívico de Santa Cruz y de la CONADE (Comité Nacional de Defensa de la Democracia), la plataforma que convocó el primer paro nacional después de las elecciones del 20 de octubre, como la de varios líderes sindicales y campesinos - como el líder de la COB Juan Huarachi o el líder de la CONTIOCAP ${ }^{10}$ Alex Villca Limaco-que también se unieron en las voces que pedían la renuncia de Morales.

La compleja normativa de la CPE y sus "espacios de indefinición estratégicos", entonces dejaron abierta la posibilidad por el gobierno del MAS para implementar políticas en línea con la agenda neoliberal de la década anterior y para pactar y legitimar su poder centralizador a través de alianzas flexibles. Sin embargo, para dar cuenta de esta dinámica, en lugar de conceptualizar los "espacios de indefinición estratégicos" de la CPE como llenos de un binarismo entre la política liberal moderna y la indígena (SCHAVELZON, 2012), hay que verlos como espacios privilegiados para visibilizar la presencia de actores y prácticas sociales que no están dispuestos a adherirse a la narrativa conceptual imperante del Estado. El espacio de excelencia de una "indefinición estratégica" reside en la noción de plurinacionalidad, que incorpora la conflictividad y las fracturas existentes entre las demandas iniciales de los movimientos sociales, el tentativo del MAS de institucionalizarlas y el intento de la élite terrateniente de desarmarlas, y desde el cual se puede comprender cómo estas fracturas explotaron en octubre 2019.

${ }^{10}$ La CONTIOCAP (Coordinadora Nacional de Defensa de los Territorios Indígenas Originarios Campesinos y Áreas Protegidas de Bolivia) es una organización que surgió en 2018 y aglutina varios grupos indígenas, campesinos y de trabajadores urbanos de Bolivia que luchan contra la implementación de proyectos extractivos en áreas protegidas y en territorios indígenas. 


\section{La Plurinacionalidad desde arriba y desde abajo}

La noción de un Estado Plurinacional, desarrollada dentro de los movimientos indígenas, plantea desafíos a la idea clásica del Estado-nación como compuesto por la unidad de los ciudadanos individuales. Sin duda, trató de superar el reconocimiento multicultural de la era neoliberal, exigiendo la erradicación de las jerarquías entre las instituciones liberales y las de origen indígenas.

Bartolomé Clavero, por ejemplo, planteando el énfasis en la matriz indígena de la conceptualización de lo plurinacional y el papel de los movimientos sociales como impulsores de la AC, ve la Constitución boliviana de 2009 como la primera en las Américas que establece las bases para un acceso universal a los derechos y al poder, y que rompe definitivamente el tracto típicamente americano del "colonialismo constitucional" o "constitucionalismo colonial" (CLAVERO, 2010, p. 199). La adopción de una firme posición anticolonial en la CPE es visible, según Clavero, en el hecho de que, mientras que dentro del "colonialismo constitucional" la minoría no indígena es la única legitimada a ejercer el poder, transformándose en mayoría legal a través de la autoridad de la ley y perpetuando por lo tanto formas coloniales de exclusión, ahora, a través del plurinacionalismo, es posible lograr un reparto igualitario del poder entre todas los diferentes sujetos que componen la sociedad Nacional-Estatal. Además, por primera vez en la historia de Bolivia, se reconoce a los indígenas como sujetos colectivos mientras que sus formas de organización política - así como sus lenguas, economías y autoridades - se reconocen en el mismo nivel jerárquico de las formas políticas liberales, a diferencia de la constitución multicultural de 1994 reformulada por el gobierno de Lozada, que garantizaba derechos a los indígenas únicamente mediante "su sujeción constitucional a un proyecto político ajeno [europeo]" (CLAVERO, 2010, p. 200).

Leyendo la CPE desde una perspectiva indígena, Clavero considera entonces que el derecho a la autodeterminación indígena, que es anterior al constitucionalismo, puede lograrse en el marco plurinacional. Albert Noguera de todos modos, consideró la perspectiva de Clavero como étnico-cultural, que no permite captar los procesos materiales que frenan el acceso real a los derechos absolutos (NOGUERA, 2008, p. 148). Noguera reconoce cómo la conceptualización de la plurinacionalidad, así como el reconocimiento de los derechos colectivos dentro de la CPE, son seguramente un avance, con pocos precedentes en el Derecho Constitucional. Pero también demuestra cómo este reconocimiento se basa en un 
nivel simbólico-lingüístico, sin promover realmente la igualdad sustancial (NOGUERA, 2008, p.157). Así, por ejemplo, junto a los símbolos republicano de la nación - la bandera nacional y el himno boliviano - se incorporan en la CPE la wiphala (la bandera del movimiento indígena aymara) y otros símbolos indígenas (Artículo 6.II); todas las 37 lenguas indígenas del territorio se reconocen como idiomas oficiales del Estado (Artículo 5.II), con la obligación para el gobierno plurinacional de utilizar, además del español, al menos una de estas lenguas en las declaraciones oficiales (Artículo 5.II); y, en el Artículo 8, la CPE asume como principios éticomorales normativos tanto los valores indígenas como los liberales. Sin embargo, por otro lado, cuando se trata de temas como el pluralismo jurídico y la gestión de los ingresos - señala Noguera - la Constitución vuelve a afirmar su poder hegemónico central, bloqueando la potencia del plurinacionalismo a través de un conjunto de normas complejas, dispositivos legales coercitivos y una pesada burocracia impuesta por la poderosa élite de la Media Luna que deformó el proyecto original del Pacto la Unidad.

Luis Tapia y Fernando Garcés también culpan a las negociaciones del MAS con la oposición oligárquica en la AC por el fracaso del plurinacionalismo y la consecuente perpetuación de un constitucionalismo neoliberal multicultural. Según Tapia, en efecto, si bien el multiculturalismo reconoce las diferencias étnicas y culturales solo asimilándolas dentro del marco liberal del Estado, la demanda inicial de plurinacionalismo elaborada dentro del Pacto de Unidad articulaba en realidad una visión política en la que el poder del Estado es compartido por las múltiples naciones que lo constituían (TAPIA, 2011, p. 3). Además, Tapia considera que el reconocimiento constitucional de los pueblos indígenas como naciones y sujetos colectivos es fundamental para el proceso de formación de un Estado plural e igualitario, ya que las comunidades indígenas ponen de manifiesto el carácter "abigarrado" del territorio boliviano y sientan las bases de un gobierno común (TAPIA, 2011, p. 145). También para Fernando Garcés, esta conceptualización inicial de la plurinacionalidad, basada en la coexistencia de varias ideas de política, cuestionaba la idea del Estado moderno y su soberanía única y absoluta sobre el territorio (GARCÉS 2011, p. 53).

De todos modos, según ambos autores, Evo Morales en la AC reordenó el concepto de plurinacionalidad desarrollado por el Pacto de Unidad, sometiéndolo al principio universalizador del Estado liberal, estableciendo una "jerarquía constitucional" (TAPIA, 2010: 157) que habría sido funcional al proyecto de centralización del poder perseguido por el MAS. Si bien es cierto que, en alguna medida, la estrategia táctica del MAS haya traicionado las 
demandas iniciales de los movimientos en su base, cabe subrayar también que un marco constitucional es insuficiente para hacer frente por sí solo a las estructuras de exclusión y opresión del Estado colonial-liberal (SAMADDAR, 2007) y para representar la multiplicidad de dimensiones, subjetividades y experiencias sociales que llevaron adelante el proceso de cambio.

Si tomamos el ejemplo de la legislación acerca de la formación de autonomías indígenas (AIOC) se muestra claramente como ésta esté en contradicción con el objetivo de la autodeterminación de los pueblos indígenas desarrollado en el Pacto de Unidad y, por lo contrario, sirva al Estado como instrumento de disciplinamento de los espacios y las subjetividades que escapan de su soberanía. En efecto, si bien algunos artículos de la CPE legitiman la formación de autonomías indígenas reconociendo sus formas de autogobierno como ejercicio de su libre determinación ${ }^{11}$, el gobierno aprobó en julio de 2010 la Ley Marco de Autonomías y Descentralización (LMAD), en la que se esbozan los requisitos específicos para la creación de estas autonomías y que pone muchos límites a su efectivo funcionamiento (COSTAS, 2018). La LMAD estableció que, una vez que una comunidad indígena haya decidido iniciar el proceso de conversión en $\mathrm{AIOC}$, debería además: en primer lugar, elaborar un Estatuto a ser aprobado por la población (LMAD, 2010: Artículos 53.I, 54. I); posteriormente, enviar el Estatuto al Tribunal Constitucional Plurinacional (TCP) para que controle su constitucionalidad y legitimidad (LMAD, 2010: Artículo 53.II); si este último aprueba el Estatuto, éste debe ser nuevamente confirmado por la población, a través de un referéndum (LMAD, 2010: Artículo 54.I, 54.II); al final, después de haber cumplido todos estos pasajes, la nueva AIOC puede elegir sus autoridades, de acuerdo con sus estatutos y con la CPE, y finalmente iniciar su gobierno autónomo (LMAD, 2010: Artículo 55). En efecto, la LMAD define con gran detalle cada uno de los procesos y requisitos que deben cumplirse para formar una $\mathrm{AIOC}$, tales como el número mínimo de población que debe tener (artículo 58), el

\footnotetext{
${ }^{11}$ Bolivia, CPE, 2009, Artículo 2: "Dada la existencia precolonial de las naciones y pueblos indígena originario campesinos y su dominio ancestral sobre sus territorios, se garantiza su libre determinación en el marco de la unidad del Estado, que consiste en su derecho a la autonomía, al autogobierno, a su cultura, al reconocimiento de sus instituciones y a la consolidación de sus entidades territoriales, conforme a esta Constitución y la ley." Bolivia, CPE, 2009, Artículo 289: "La autonomía indígena originaria campesina consiste en el autogobierno como ejercicio de la libre determinación de las naciones y los pueblos indígena originario campesinos, cuya población comparte territorio, cultura, historia, lenguas, y organización o instituciones jurídicas, políticas, sociales y económicas propias."
} 
límite máximo de días para la celebración del referéndum de aprobación del estatuto (artículo 54.V), cuántas personas deben elaborar el estatuto (artículo 53.I) y otros.

En consecuencia, es evidente no sólo cómo todos estos pasajes complican y frenan la aplicación de la AIOC, sino también la intención del Estado de controlar cada detalle de su territorio y de su población y de regular su vida social, eliminando el concepto de libre determinación de los pueblos indígenas. Las ambigüedades y la complejidad son tan densas que si bien 22 comunidades indígenas empezaron el proceso para volverse en AIOC en 2009 Cuando se aprobó la CPE, hasta hoy sólo hay tres AIOC oficialmente legitimadas en Bolivia: Charagua en el departamento de Santa Cruz, establecida en 2016; Uru Chipaya que se formó en 2017 en el departamento de Oruro; Raqaypampa que se conformó en 2018 en el departamento de Cochabamba.

De esta manera, el marco constitucional, al poner énfasis en los derechos colectivos alcanzados por la lucha indígena, no reconoce el carácter disciplinario de esos derechos colectivos (RUDAN, 2014) que, en los últimos años, a través de su definición y reconocimiento "desde arriba", fueron funcionales al mandato coercitivo del Estado y a los procesos neoliberales (HALE, 2005, p. 11). El problema, en el plano teórico, reside en el hecho de que la propia forma de reconocimiento es un medio para gobernar que subsume las prácticas indígenas en la lógica constitucional plurinacional. Al mismo tiempo, legitimando la presencia de las comunidades indígenas sólo como unidades homogéneas, el marco constitucional niega las líneas de conflictos y divisiones que atraviesan la comunidad, como las sexuales o entre generaciones. Además, como explica Lucas Bessire tomando el caso de los Ayoreos, este reconocimiento constitucional de las comunidades indígenas como núcleos cerrados crea una situación de hipermarginalidad de otros grupos minoritarios indígenas que no residen en la comunidad o que no tienen poder decisional en esa (BESSIRE, 2014).

Lo que se puede afirmar sobre el caso boliviano, en cambio, es el fracaso del marco constitucional plurinacional al "apoderarse" de la complejidad de un país poscolonial y de los procesos recientes de levantamientos de actores desde abajo, así como el fracaso del intento del MAS de nombrarse representante de los heterogéneos sujetos políticos de la sociedad boliviana. De hecho, la lógica disciplinante constitucional se combina con los dispositivos coercitivos y la agenda económica empleada por el MAS para perpetuar esta lógica y controlar la autodeterminación indígena. El caso de las autonomías indígenas puede servir también en este caso para mostrar cómo el MAS intentó producir un consenso incuestionable 
sobre el carácter de la AIOC y el significado de la indigenidad, según el cual pudo legitimar su programa político y perseguir el desarrollo económico.

\section{El Estado Indígena}

Para completar su descabellada sobrerregulación, la LMAD obliga a las comunidades indígenas que quieren formar una $\mathrm{AIOC}$ a certificar su territorio como ancestral y su población como nativa (Artículo 56.I). Claramente, la indigenidad no es una categoría fija y naturalizada que se basa en tractos biológicos, sino que es una formulación contingente histórica que cambia con el tiempo y asume su significado no (sólo) desde el interior de una cultura particular sino en relación con el espacio conflictivo en el que se forma. Así, mientras que el artículo 30.1 de la CPE indica quiénes son los indígenas de una manera que se abre a diferentes interpretaciones ${ }^{12}$, la LMAD obliga las comunidades que quieran convertirse en AIOC a someterse a un proceso, supervisado por "expertos del Estado", que debe certificar su ancestralidad. El Estado sigue siendo entonces el diseñador de los regímenes de ciudadanía y, al mismo tiempo que concede la plena ciudadanía a los indígenas, modela sus subjetividades y establece las reglas de su accesibilidad a la política, homogeneizando y fijando el significado de la indigenidad para legitimar su propia agenda.

La valorización de la indigeneidad y de la condición campesina de la sociedad boliviana fue una de las tácticas más exitosas operada por el gobierno del MAS para crear cohesión social entre los varios movimientos que quería representar. Desde los hábitos de Evo Morales hasta sus discursos, se puede ver cómo el presidente indio empleó una retórica y un simbolismo indígena para convertirse en el promotor de un nuevo Estado, en el que se valora la indigenidad. Sin embargo, esta valorización fue perseguida sólo de manera instrumental y folclórica, mientras que el significado de la indigeneidad es decidido incontestablemente por el aparato estatal, deslegitimando el desacuerdo. Este tipo de indigenidad asumida por el MAS a través de prácticas performativas que dan la apariencia que los indios están gobernando, es la que la socióloga aymara Silvia Rivera Cusicanqui,

\footnotetext{
12 Bolivia, CPE, 2009, Artículo 30.I: "Es nación y pueblo indígena originario campesino toda la colectividad humana que comparta identidad cultural, idioma, tradición histórica, instituciones, territorialidad y cosmovisión, cuya existencia es anterior a la invasión colonial española."
} 
torciendo el concepto de esencialismo estratégico de Gayatri Spivak (1996), llama una "etnicidad estratégica" (CUSICANOUI, 2014, p.9). Según la autora, la etnicidad estratégica del MAS está en continuación con lo que conceptualizó como "Indio Permitido" (CUSICANOUI, 2008; HALE, MILLIMAN, 2005), o sea el sujeto indígena reconocido como ciudadano de derechos con las reformas multiculturales de los años go solo en cuanto minoría a proteger y a "aculturar" en los derechos neoliberales, e "incorporar" al mercado como comercializadores de su propio patrimonio cultural (CUSICANOUI, 2014, p.34; HALE, MILLIMAN, 2005, p. 284). Entonces, la "etnicidad estratégica" fue funcional al MAS para "encubrir las continuidades (neo)coloniales del pasado, bajo el rótulo de 'proceso de cambio'" (CUSICANQUI, 2014, p. 37), mientras que atrapaba los indígenas en una categoría esencialista y ontológicamente diferente en la que no había espacio para la dinamicidad y procesualidad política que la identidad indígena incorpora y cuya relatividad es fundamental para el surgimiento de procesos de politización.

En realidad, en un primero momento el MAS sucedió en consolidar "esta etnicidad estratégica" también a través de su política económica. En efecto, la idea de base del llamado capitalismo andino-amazónico ${ }^{13}$ teorizado por el vicepresidente Álvaro García Linera, apuntaba a promover la emancipación económica de la mayoría de la población indígena y campesina de Bolivia, utilizando los ingresos de la exportación de materias primas para impulsar la industrialización en las comunidades indígenas rurales con el fin de proporcionar a los habitantes de las zonas rurales sus medios de producción y ampliar sus capacidades de consumo (GARCIA LINERA, 2006). Imponiendo el papel centralizador del Estado Plurinacional como impulsor de la modernización, el MAS valorizó así las pluralidades de las economías indígenas y comunitarias como núcleos activos en esta modernización. De esta manera el MAS pudo materializar su retórica indigenista con una política económica que prometía beneficios para las comunidades y, como consecuencia, reformular el régimen de ciudadanía del Estado: si en el marco de la Revolución Nacional con la sindicalización de la clase obrera los indígenas tenían que "esconder" sus tractos anacrónicos para formar parte del moderno proletariado urbano, y si el modelo del neoliberalismo multicultural legitimaba

\footnotetext{
13 Para profundizar la teoría del capitalismo andino-amazónico elaborada por el ex vicepresidente véase Garcia Linera $(2006 ; 2008 ; 2009 b)$.
} 
las comunidades indígenas sólo como minorías a tutelar, ahora los indígenas pueden afirmar con orgullo su identidad en el marco estatal, ya que las propias practicas indígenas se convirtieron en las propulsoras de la modernidad. Durante el primer mandato de Morales, esta estrategia fue muy exitosa, gracias también al aumento de los precios de los recursos naturales en el mercado mundial, que hicieron crecer la economía del país en un 5,2 por ciento anual de 2006 a 2009 (POSTERO, 2017, p.98).

Si bien esta política económica fue funcional al intento de cohesión social buscado por Morales, el MAS tuvo que enfrentarse al poder de la Media Luna, que no estaba dispuesta a perder parte de sus ganancias del comercio en favor de una mayor redistribución de tierras. Al mismo tiempo el MAS debió tener en cuenta las cadenas de valor del capital global que, en los últimos años al interior del marco de los proyectos de integración regional como la UNASUR y el MERCOSUR, han visto una aceleración en la organización de la producción y circulación mundial y la afirmación de una "racionalidad logística" que se impuso como una lógica capaz de afectar a nuevas formas de soberanía territorial y de gobierno político ${ }^{14}$. Estos factores llevaron el MAS a hacer varias concesiones a la élite terrateniente: por ejemplo, a través del Plan de Desarrollo Económico y Social de 2015, se aprobó la ampliación de la frontera agrícola de 3,5 a 4,7 millones de hectáreas en detrimento de los territorios indígenas (MCKAY, 2018, p. 179). Por otro lado, la mayoría de los ingresos excedentes de exportación no fueron investidos en el desarrollo de las comunidades rurales como se había inicialmente declarado, sino en proyectos de minería e infraestructura funcionales a la expansión ilimitada del capitalismo extractivista y de la interconexión de la región con los mercados globales: entre 2010 y 2015 , el $84 \%$ de los ingresos de exportación se reinvirtieron en proyectos extractivos, mientras que sólo el $16 \%$ se invirtió en salud, educación y erradicación de la pobreza extrema (VILLEGAS, 2013, p.171). Por último, se acordó con China la mayor financiación jamás otorgada al Estado boliviano (7.500 millones de dólares, es decir, el 17\% de su PIB), destinada a un ambicioso programa de megaproyectos en la región - incluidas infraestructuras, presas hidroeléctricas y minas - pero concesionada totalmente a empresas chinas para su ejecución (GANDARILLAS, 2015, p.115).

\footnotetext{
${ }^{14}$ Véase: Grappi (2016); Benvegnù, Cuppini, Frapporti, Milesi, Pirone (coord.), 2020.
} 
Podemos entonces afirmar que, aunque a nivel retórico el MAS instrumentalizara los valores indígenas para apoyar el desarrollo económico del país, en realidad siguió condenando el país a la economía primaria, substituyendo el Consenso de Washington de los años neoliberales por lo que Maristella Svampa llamó el "Consenso de los Commodities", que se basa en la exportación masiva de materias primas en el mercado internacional que vuelve las economías latinoamericanas dependientes de los precios de los recursos en el mercado global (SVAMPA, 2012) y aumenta fenómenos de desposesión (HARVEY, 2004) de los territorios indígenas y de ampliación del monocultivo (SVAMPA, 2012) ${ }^{15}$.

Estas contradicciones en la gestión política del MAS salieron a la luz en modo contundente en 2012, cuando el gobierno reprimió brutalmente la marcha de los pueblos indígenas del Beni contra la construcción de una carretera - financiada por el Banco Nacional de Desarrollo de Brasil y parte integrante de la infraestructura del megaproyecto IIRSA ${ }^{16}$ que debía conectar el Trópico de Cochabamba con la frontera brasileña, pasando a través del territorio indígena protegido del TIPNIS ${ }^{17}$. Esta Marcha, que, en línea con la Marcha por la Dignidad de 1990, fue una ocasión por los movimientos indígenas y campesinos para ampliar la movilización populary poner de manifiesto todas las fracturas con el gobierno del MAS, no solo fue brutalmente reprimida por las fuerzas armadas, sino que los manifestantes fueron también criminalizados como "salvajes que impiden la modernización de la nación" y que tienen vínculos con Estados Unidos para frenar el desarrollo económico de Bolivia (POSTERO, 2017, p. 128,129). Este conflicto marcó el punto de no retorno para la fractura entre el MAS y algunos movimientos sociales y provocó también una desegregación de muchas organizaciones sociales e indígenas bolivianas que empezaron a dividirse entre los partidarios y los opositores del MAS. Se puso así fin a la masiva articulación del Pacto de Unidad y a la alianza entre los varios sectores del campo popular que habían sido fundamentales para empujar el proceso de cambio. De hecho, el MAS llamó las organizaciones que todavía continuaron siéndole leales a movilizarse contra los "falsos

\footnotetext{
15 Véase también: Gudynas (2012).

${ }^{16}$ Para una profundización sobre el plan IIRSA véase: Peregalli (2020), in Benvegnù, Cuppini, Frapporti, Milesi, Pirone (coord.).

${ }_{17}$ Para profundizar el conflicto del TIPNIS véase: Bautista (2012); Paz (2012); Saavedra (2013).
} 
indígenas" que estaban marchando, intensificando el conflicto entre las facciones (LÓPEZ Y MAKARÁN, 2018, p. 194-204).

Desde ese momento el declino del MAS cual representante de los movimientos populares ha sido inexorable y llevó a la multiplicación de las líneas de conflictos y fracturas con las organizaciones sociales. Por un lado, el MAS fortificó su alianza con el sector de la Media Luna a través de una serie de acuerdos comerciales que habrían sido funcionales para mantenerlo al poder, mientras que, por el otro, reforzó su alianza con las organizaciones indígenas y campesinas que seguían de su lado, criminalizando y deslegitimando las que no pudo cooptar.

Para mantener su alianza con la élite terrateniente, el MAS empezó, en agosto de 2017, nuevos acuerdos estratégicos con China para regular la venta de productos bolivianos como la soja, la carne y la quinua al mercado chino favoreciendo las asociaciones de productores de la Media Luna. El primer acuerdo comercial se concertó en diciembre de 2018 con el envío de 40 toneladas de quinua al Estado asiático. Posteriormente, en marzo de 2019, Evo Morales aprobó una negociación para introducir la siembra de dos nuevas variedades de soja transgénica y aumentar de 250.000 hectáreas el territorio agrícola reservado para su producción - aumentándolo de 1,3 a casi 1,6 millones de hectáreas - con el objetivo, por un lado, de producir 100 millones de litros de combustible vegetal al año y, por otro, de abrirse al principal mercado de la soja, China, que requiere alrededor de 90 millones de toneladas de soja cada año, lo que equivale al $65 \%$ de las importaciones mundiales ${ }^{18}$. Por último, el 26 de abril de 2019, el Ministro de Relaciones Exteriores de Bolivia, Diego Pary, y el Ministro de Aduanas de China, Ni Yuefeng, firmaron un acuerdo que abrió la puerta a la exportación de carne de vacuno boliviana a China, con un objetivo de 117.000 toneladas anuales para 2025, que habría servido al MAS para mantener su alianza con Federación de Ganaderos de Santa CrUZ (FEGASACRUZ) ${ }^{19}$.

Por otro lado, para asegurarse la alianza con las organizaciones indígenas que todavía no se habían levantado contra su gobierno, el MAS empezó a actuar una serie de

18 Disponible en: https://www.paginasiete.bo/economia/2018/12/12/anapo-valor-de-exportacion-de-soyallega-us-480-millones-hasta-octubre-202902.html Acceso el 15/06/2020; https://es.mongabay.com/2019/04/bolivia-gobierno-soya-transgenica/. Acceso el 15 jun. 2020.

19 Disponible en: https://eldeber.com.bo/132830_se-abre-la-exportacion-de-carne-a-china-y-ganaderospreven-crecer-hasta-un-5 Acceso el 15 jun. 2020. 
irregularidades en el Fondo de Desarrollo Indígena Originario Campesino (FONDIOC). EI Fondo, pensado originalmente para suportar la industrialización de los territorios indígenas y desarrollar proyectos en las comunidades, acabó siendo un instrumento de corrupción usado por el MAS para mantener sus lazos con algunos dirigentes sindicales y campesinos y corromper algunas secciones de las organizaciones indígenas mientras que deslegitimaba otras (AYO, 2016, p.6). Cuando estas irregularidades salieron a la luz en 2015, el MAS logró limpiarse de las acusaciones directas y, por lo tanto, se encarcelaron a una serie de dirigentes indígenas y campesinos acusados de haber recibido dinero ilegalmente del Fondo Indígena (SAAVEDRA, 2015). Además, en varias ocasiones, Morales adoptó estrategias más sutiles para corromper los líderes indígenas: a menudo el MAS infiltró personal gubernamental en los movimientos indígenas haciéndolos pasar por investigadores o trabajadores de ONG, a fin de obtener información sobre las estrategias políticas y los territorios de sus adversarios, como pasó en el conflicto del TIPNIS (LÓPEZ Y MAKARÁN, 2018, p.196); o, incluso, el MAS infiltró en las organizaciones sociales personas afines a su gobierno que decidieron arbitrariamente remplazar y substituir varios líderes indígenas electos colectivamente por las comunidades, como pasó en el caso de la CIDOB y de la APG, que se encontraron desde 2015 totalmente divididas entre una facción "masista", con líderes elegidos por el propio MAS, y una facción "orgánica", con líderes elegidos por las asambleas indígenas (LÓPEZ Y MAKARÁN, 2018, p.196). Por fin, también el sistema de redistribución de tierras fue explotado por el MAS para asegurarse la fidelidad de su base electoral. De acuerdo con los datos INRA (Instituto Nacional de Reforma Agraria) proporcionados en marzo de este año, se aprobaron más de 1.400 asignaciones de tierras en el país entre 2013 y 2018, de las cuales 900 en la zona de Chiquitanía - en el departamento de Santa Cruz. Pero, una encuesta realizada por la Fundación Tierra mostró que estas asignaciones siguieron una política de redistribución a favor de la población pobre de las zonas rurales bolivianas, como establecen los principios de la Reforma Agraria, sino que siguieron los intereses del sector agrícola boliviano que apoya al $\mathrm{MAS}^{20}$. Gran parte de la tierra fiscal disponible fue asignada a personas que viven en áreas urbanas o a pequeños productores de sectores campesinos o indígenas aliados al MAS,

\footnotetext{
${ }^{20}$ Véase: https://www.paginasiete.bo/sociedad/2019/9/29/con-200-de-deforestacion-bolivia-cambia-bosquespor-la-agroindustria-232500.html. Acceso el 15 jun., 2020.
} 
reubicándolos en la parte oriental del país, violando así el artículo 43 de la Ley 1715 de la Reforma Agraria que establece que la redistribución de la tierra fiscal debe favorecer a las comunidades indígenas y campesinas sin tierra y que ya residen en el departamento en el que se encuentra la parcela a ser asignada ${ }^{21}$. De esta manera, el MAS logró asegurarse de una sola vez una sólida base de votantes en el departamento de Santa Cruz - un área históricamente contraria a su gobierno -, ya que las asignaciones están vinculadas a la inscripción en el colegio electoral del departamento de reubicación, y un mayor control de la producción agrícola y de los recursos naturales en la zona. Además, esta forma de clientelismo en la redistribución de tierras fue uno de los factores que se evaluaron como detonantes de los incendios que explotaron en la Amazonia boliviana en agosto 2019. En efecto, la mayoría de las tierras fueron redistribuidas a pequeños campesinos y productores para incrementar la producción agrícola de la zona. Este factor, junto con la aprobación, un mes antes del inicio de los incendios, del Decreto 3973 que autoriza la deforestación mediante quemas controladas en los departamentos de Santa Cruz y Beni para el desarrollo de actividades agrícolas en terrenos privados y comunitarios, fueron las causas de los incendios que quemaron alrededor de 5,3 millones de hectáreas - el mismo tamaño que todo Costa Rica y que dañaron hasta 30 reservas naturales y áreas protegidas. Pero, detrás de este Decreto hay otras dos leyes (N. 337 y N. 741) que condonaron las hectáreas deforestadas sin autorización entre el 12 de julio de 1996 y el 31 de diciembre de 2011 - por un total de 1.582.807 hectáreas - y el desmonte de hasta 20 hectáreas en propiedades privadas, comunitarias o colectivas en proceso de saneamiento o tituladas y en asentamientos humanos legalmente establecidos con resolución de autorización, para facilitar el desarrollo de actividades agrícolas y pecuarias en todo el país ${ }^{22}$. Todas estas medidas correspondieron, por lo tanto, a un interés político por parte del gobierno en el intento de continuar a pactar su poder y ganar las elecciones de 2019.

${ }^{21}$ Véase: http://www.ftierra.org/index.php/component/attachments/download/185 Acceso el 15 jun. 2020; https://www.lostiempos.com/actualidad/pais/20190915/asentamientos-se-extienden-beni-pando-territoriosindigenas?fbclid=IwARozZnojWChGXWwHCARWO 5 t5pcCXEwOldygtguYBcBStkz6xzYWgoZkNyh4. Acceso el 15 jun. 2020.

22 Disponible en: https://www.paginasiete.bo/sociedad/2019/9/29/con-200-de-deforestacion-bolivia-cambiabosques-por-la-agroindustria-232500.html Acceso el 15 jun. 2020. 


\section{La derrota de Morales y la rearticulación de los movimientos sociales}

La descalificación y la persecución penal de los líderes que se oponían al gobierno, la cooptación de sectores de movimientos sociales que todavía veían en el MAS un medio para obtener recursos y poder político, el fomento a posicionarse en contra de quien rechazaba la implementación de proyectos extractivos e infraestructurales, se convirtieron en prácticas rutinarias del gobierno en los últimos anos. El intento del MAS de dirigir el proceso de cambio, entonces, llevó a la contracción de los espacios de politización que el modelo masista había ofrecido en un primer momento al bloque social popular, indígena y campesino. Sin embargo, no hay que olvidar que el gobierno del MAS abrió efectivamente algunos espacios de politización que fueron utilizados estratégicamente durante mucho tiempo por los movimientos sociales para obtener partes de la riqueza y el poder político a detrimento de la élite terrateniente. Estos factores dieron lugar a un aumento de protestas y levantamientos sociales en el último mandato de Morales, encabezadas tanto por sectores conservadores de la sociedad boliviana, como por los heterogéneos sujetos que habían inicialmente empujado el paradigma plurinacional, si bien estas movilizaciones fueron más espontaneas y más desarticuladas de las que animaron el comienzo de los años 2000.

La división provocada por las políticas masistas entre las mayorías de las organizaciones que hacían parte de la forma multitud durante el ciclo rebelde dio al paso a la rearticulación de los movimientos sociales y a la reconfiguración de sus dinámicas y prácticas, mientras que la alianza del MAS con los sectores empresariales orientales, si bien fue funcional al mantenimiento de su gobierno, acabó por conceder el tiempo y el espacio gracias al cual las fuerzas neoliberales y conservadoras fueron capaces de construir su propia contraofensiva, que luego se montó a la carga del "autoritarismo" reivindicada también por los movimientos sociales. Por un lado, se creó así una convergencia entre algunas facciones "orgánicas" de los movimientos sociales, los Comités Cívicos departamentales históricamente compuestos por la oligarquía terrateniente de los departamentos $-y$, más recientemente, la CONADE. Si bien el descontento de las organizaciones sociales miraba a deslegitimar el MAS cual portavoz de los movimientos y a retomar los espacios de poder que el proceso de cambio les había prometido, mientras que los Comité Cívicos promovían un discurso conservador y antisocialista y la CONADE desarrollaba un discurso más liberal en defensa de la democracia y de los derechos de los ciudadanos boliviano contra la dictadura 
de Morales, las varias facciones empezaron a coincidir en pedir la renuncia de Evo en el último mandado del presidente Indio.

Por otro lado, la separación de las organizaciones sociales dio lugar a nuevas formas de articulación entre movimientos antes desconectados. En efecto, la imposibilidad de muchos indígenas de articularse bajo sus organizaciones tradicionales, que a menudo habían sido cooptadas por el MAS, los llevó a organizar sus luchas en contra de la desposesión de sus territorios junto con otras comunidades rurales afectadas por estas dinámicas del capital global y activistas urbanos que solidarizaban con el tema. Un ejemplo de esta reconfiguración es el surgimiento en 2018 de la CONTIOCAP (Coordinadora Nacional de Defensa de los Territorios Indígenas Originarios Campesinos y Áreas Protegidas de Bolivia), una organización que trasciende las estructuras de organización política hegemónica de las comunidades indígenas (como la APG y la CIDOB), y que aglutina varios activistas que luchan en contra de la implementación de proyectos extractivos en territorios comunitarios y áreas protegidas, también enfrentándose a los líderes indígenas y campesinos afiliados al MAS. Esta nueva forma de lucha permite "escapar" de la cristalización operada por el MAS de la identidad indígena como algo homogéneo y ontológicamente diferente, y recuperar el sentido procesual y relacional de la identidad indígena mostrando como las contradicciones y tensiones están incorporadas en su definición. Además, en muchas comunidades indígenas empezaron a surgir varias organizaciones de mujeres indígenas, como por ejemplo la OMIGB (Organización de Mujeres Indígenas Guaraní de Bolivia), la primera asociación autónoma de mujeres guaraníes. Éstas empezaron a luchar de forma autónoma en contra de la política de Morales, desvinculándose tanto de las organizaciones tradicionales que continúan a ser cruzadas por relaciones patriarcales, como de las ONGs que siguen suportando la política de las comunidades indígenas de manera a veces contradictoria y paternalista ${ }^{23}$. Así, las mujeres indígenas lograron volverse en una fuerza política que no podía ser más ignorada por los líderes indígenas y sucedieron en elaborar una crítica potente a las políticas extractivas del gobierno masista ${ }^{24}$, conectándose con el movimiento feminista transnacional que, desde el

\footnotetext{
${ }^{23}$ Para el caso específico de la rearticulación de los movimientos indígenas de tierras bajas y el surgimiento de las organizaciones de mujeres véase: De Ambroggi (2020), in Benvegnù, Cuppini, Frapporti, Milesi, Pirone; Cuellar (2019).

24 Véase: Cuellar (2019); Gutierréz Aguilar (2017); Saavedra (2019).
} 
8 de marzo 2017, con la primera huelga feminista global, se impuso masivamente en la escena política como "un medio para cuestionar todo el orden neoliberal en el mismo momento en que la violencia patriarcal había empezado a ser reconocida como fundamental para ello" (RUDAN, 2018, p.242)25. Esta capacidad de cuestionar las bases patriarcales, racistas y capitalistas de la sociedad global partiendo de la posición parcial de la mujer, llevó el movimiento feminista a ser una potencia capaz de articular y fortalecer a su interior varias luchas manteniendo las especificidades de cada una y las diferencias que la componen. En este sentido, el lazo entre algunas activistas indígenas y el movimiento feminista global ha sido fundamental tanto para la valorización de prácticas de luchas y discursos indígenas como parte integrante del feminismo global, como para brindar solidaridad transnacional a varias organizaciones de mujeres indígenas.

Esta rearticulación de movimientos es la que animó las protestas de octubre 2019. Siguiendo la conceptualización del término gramsciano de "revolución pasiva" desarrollada por Massimo Modonesi (2017), se podría afirmar que los catorce años de gobierno masista intentaron desarrollar un proceso de modernización y de implementación de la plurinacionalidad desde arriba que, si bien reconoce parcialmente las demandas desde abajo producidas por los movimientos sociales, tiende a desactivarlas y pasivarlas mediante la reducción de los espacios de antagonismo y autonomía (MODONESI, 2017, p 17). Según Modonesi este tipo de "revolución pasiva" no implica ni la restauración total del orden anterior, ni la revolución radical, sino que sirve a quien la desarrolla - en este caso el MAS para garantizar y legitimar las estructuras jerárquicas de su poder y acaba por restablecer la iniciativa política de fracciones de las clases dominantes mientras que al mismo tiempo opera una re-subalternización de los sujetos políticos antagónicos y una cooptación de sus capacidades de movilización social (MODONESI, 2017).

El intento del artículo es justamente de demonstrar cómo, en primavera de 2019, tanto el rápido predominio de la élite cruceña y de los Comités Cívicos departamentales en las protestas como la disgregación de los movimientos populares, fueron efectos de la "revolución pasiva" operada por el MAS y de su estrategia política que acabó por dar continuidad a las políticas neoliberales de los años go aún si en el interior de un paradigma

25 Véase también: Carrillo Vidal et al. (2020); Gago (2019); Menendez (2017). 
estatal renovado por la presencia indígena y campesina. Sin embargo, como se afirmó en el comienzo, un marco institucional no es suficiente para dar cuenta del abigarramiento de la sociedad boliviana y de la forma en el que esta se configuró durante los levantamientos de octubre. De hecho, si bien el MAS sucedió en debilitar el poder de veto que los movimientos sociales hicieron valer en los años 2000 y durante el proceso constituyente, el continuo entrelazamiento de fracturas y líneas de conflicto étnicas, de clase y sexuales abrió espacios políticos novedosos dentro de las formas "hegemónicas" de organización social campesina, indígena y sindical que, a su vez, dieron vida a nuevos procesos de politización antagónicos. En este sentido, el ejemplo más significativo de la imposibilidad de dar sólo una lectura institucional a la crisis electoral es el poderoso y simultáneo surgimiento de varios grupos feministas que, en medio de la crisis y siguiendo la idea lanzada por el colectivo Mujeres Creando, convocaron un Parlamento de las Mujeres en las principales ciudades bolivianas, es decir una asamblea pública que mira a construir un espacio político feminista en el que abordar el conflicto boliviano para dar una respuesta autónoma tanto a las políticas de Morales como a la avanzada de las fuerzas reaccionarias con el gobierno de Añez.

Por lo tanto, el violento fin de Morales era previsible considerando tanto las fracturas demasiado amplias que se habían abierto en 14 años de su gobierno entre varios sectores de la sociedad boliviana, cuanto la insistencia del ex presidente en su reelección después que el referéndum del 21 febrero 2016 había prohibido la cuarta postulación del binomio Morales García Linera a la presidencia de Bolivia (LÓPEZ Y MAKARÁN, 2018, p. 191). Estos factores llevaron al rechazo total a un modelo en el que la figura de Morales se había establecido como un centro institucional de mediación entre el poder político, los movimientos sociales y la élite terrateniente. Desde este punto de vista, es significativo el hecho de que el declino del proceso de cambio se consumó principalmente en torno a las políticas extractivas del MAS, y a sus corolarios de cooptación de sectores indígenas y campesinos a exclusión de otros. Este factor invita a pensar tanto en el dilema que enfrentaron todos los gobiernos del "ciclo progresivo" y a su fin, como en las consecuencias que puede tener en todo el continente latinoamericano la reciente victoria aplastante del MAS en las elecciones del 18 de octubre 2020, después de un ano de gobierno neoliberal y reaccionario. El "neo-extractivismo progresista" (GUDYNAS, 2012) es la política que durante un tiempo permitió hacer funcionar la economía y reducir la pobreza. Al mismo tiempo, para lograr estos objetivos, necesariamente ha creado procesos de politización obrera, 
campesina, feminista e indígena y, por lo tanto, líneas de fractura política de las que la derecha conservadora aprovechó para recuperar un poder que considera su monopolio exclusivo. Sin embargo, las varias manifestaciones que llevaron millones de personas de diferentes sectores populares a salir en las calles la primavera pasada no solo en Bolivia sino en toda América Latina, demuestran la capacidad de antagonismo que los movimientos sociales siguen teniendo en contra de las nuevas dinámicas de poder continentales en las que se combinan políticas neoliberales de explotación y precarización con la avanzada reaccionaria. Igualmente, la reciente reelección del MAS en Bolivia con el binomio Arce Choquehuanca con más del $55 \%$ de votos, así como el triunfo del "sí" en el referéndum chileno para abrogar la constitución de Pinochet, prueban como los movimientos sociales de estos países no han perdido la capacidad de levantarse y organizarse en este último ano en el que la brutalidad racista y fascista de sus gobiernos se ha combinado a una gestión empresarial y neoliberal de la pandemia de coronavirus. En el caso de Bolivia, la vuelta del MAS tendrá que lidiar con ese "poder de veto" que los movimientos sociales demostraron seguir teniendo: si la decisión de postular Choquehuanca a la vicepresidencia fue favorable para restablecer la confianza de los sectores campesinos e indígenas andinos al MAS y a sus promesas de reabrir el proceso de cambio ${ }^{26}$, aún hay que ganarse la confianza de la mayoría de los indígenas del oriente, más afectados por los proyectos extractivos, que siguen criticando el MAS y afirmando que ningún gobierno puede apropiarse del proceso de cambio empezado y desarrollado autónomamente por las organizaciones sociales e indígenas.

Si bien estos levantamientos del último año tienen sus propias especificidades y diferencias a segunda de los contextos y países en las que se dieron, marcaron irrevocablemente un hito histórico para América Latina y un punto de ruptura definitivo en la relación entre los movimientos sociales y el Estado, así como una rearticulación de dinámicas entre los movimientos mismos, cuyo futuro sigue abierto y en disputa y que parece no tenga ninguna intención de interrumpirse ante el actual contexto de pandemia global. 


\section{Referencias}

ALBÓ, Xavier. Los Guaraní-Chiriguano 3. La comunidad hoy. La Paz: CIPCA, 1990.

BAUTISTA, R. et al. (coord.). La victoria indígena del TIPNIS. La Paz: Autodeterminación, 2012.

AYO, Diego. La verdad Sobre el Fondo Indígena. La Paz: Fundación Pasoskanki, 2016.

BENVEGNÙ, Carlotta; CUPPINI, Niccolò; FRAPPORTI, Mattia; MILESI, Floriano; PIRONE, Maurilio (coord.). Logistica e America Latina. Bologna: Università di Bologna, 2020

BESSIRE, Lucas. The Rise of Indigenous Hypermarginality. Native Culture as a Neoliberal Politics of Life. In: Current Anthropology, v. 55, n 3, p. 276-295, 2014.

BOLIVIA. Ley N. 1715 del 18 de octubre de 1996. Gaceta Oficial de Bolivia. La Paz. Disponible en: http://www.gacetaoficialdebolivia.gob.bo/normas/buscar/1715. Acceso: el 15 jun. 2020.

BOLIVIA. Ley N. 31 del 19 julio de 2010. Ley Marco de Autonomías y Descentralización. Gaceta Oficial de Bolivia. La Paz. Disponible en: http://www.gacetaoficialdebolivia.gob.bo/normas/buscar/31. Acceso el: 13/06/2020.

BOLIVIA. Ley N. 337 del 11 de enero de 2013. Ley de Apoyo a la Producción de Alimentos y Restitución de Bosques. Gaceta Oficial de Bolivia. La Paz. Disponible en: http://www.gacetaoficialdebolivia.gob.bo/normas/buscar/337. Acceso: el 15/06/2020.

BOLIVIA. Ley N. 74129 de septiembre de 2015. Ley de autorización de desmonte hasta 20 hectáreas para pequeñas propiedades y propiedades comunitarias o colectivas para actividades agrícolas y pecuarias. Gaceta Oficial de Bolivia. La Paz. Disponible en: http://www.gacetaoficialdebolivia.gob.bo/normas/buscar/741. Acceso: el 15/06/2020.

BOLIVIA. Decreto Supremo 3973 de 10 de julio 2019. Gaceta Oficial de Bolivia. La Paz. Disponible en: http://www.gacetaoficialdebolivia.gob.bo/edicions/view/1177NEC. Acceso el: $15 / 06 / 2020$.

BOLIVIA. Pacto de Unidad. Propuesta para la nueva Constitución Política del Estado: Por un Estado Unitario Plurinacional Comunitario, Libre, Independiente, Soberano, Democrático y Social. Sucre, 05 ago., 2006.

BOLIVIA. Constitución Política del Estado Plurinacional de Bolivia: promulgada el 7 de febrero 2009. El Alto.

CANESSA, Andrew. Who is indigenous? Self-Identification, Indigeneity, And Claims to Justice in Contemporary Bolivia. Urban Anthropology, v. 36, n.3, p. 195-237, 2007. 
CARRILLO VIDAL, Alondra et al. La Internacional Feminista. Luchas en los territorios y contra el neoliberalismo. Buenos Aires: Tinta Limón, 2020.

COMBĖS, Isabelle; SAIGNES, Thierry. Alter Ego. Naissance de l'identité chiriguano. Paris: Éditions de l'EHESS, 1991.

CHÁVEZ, Marxa Nadia León. "Autonomías indígenas" y "Estado Plurinacional". Proyectos políticos de los movimientos indígenas y campesinos en Bolivia. OSAL, n.24, p. 51-71, 2008.

CLAVERO, Bartolomé. Apunte para la ubicación de la Constitución de Bolivia. Revista Española de Derecho Constitucional, n. 89, p. 195-217, 2010.

CUAREY, Elías. Asamblea del Peublo Guaraní. Un breve repaso a su historia. Bolivia: Gráfica Impora, 2015.

CUELLAR, Claudia. ¡CON NOSOTRAS NO!: La organización autónoma de mujeres indígenas de Tierras Bajas un prisma para entender el presente en Bolivia.

CONFLUÊNCIAS, v. 21, n.2, p. 273-287, 2019.

DUNKERLY, James. Bolivia: Revolution and the Power of History in the Present. London: Institute for the Study of the Americas, 2007.

GAGO, Veronica. La potencia feminista. O el deseo de cambiarlo todo. Madrid: Traficantes de Sueños, 2019.

GAGO, Veronica; MEZZADRA, Sandro. In the wake of the plebeian revolt: Social movements, 'progressive' governments, and the politics of autonomy in Latin America.

Anthropological Theory, v. 17, n. 4. 2017, p. 474-496.

GAGO, Veronica; SZTULWARK, DIEGO. The Temporality of Social Struggle at the End of the "Progressive" Cycle in Latin America. The South Atlantic Quarterly, v. 115, n. 3, p. 605$614,2016$.

GANDARILLAS, M. Antonio. Bolivia, entre el extractivismo y el buen vivir: propuestas y alternativas de las organizaciones de la sociedad civil. Lan Harremanak, v. 2, n. 33, p. 113$125,2015$.

GARCÉS, Fernando. The Domestication of Indigenous Autonomies in Bolivia: From the Pact of Unity to the New Constitution. En: FABRICANT, Nicole; GUSTAFSON, Bret (coord.), Remapping Bolivia: Resources, Territory, and Indigeneity in a Plurinational State. Santa Fe, NM: School for Advanced Research, p. 46-67, 2011.

GARCÍA LINERA, Álvaro. El "capitalismo andino-amazónico". Le Monde Diplomatique, Santiago de Chile, 1, 2006. 
GARCÍA LINERA, Álvaro. Del liberalismo al Modelo Nacional Productivo. Los ciclos de la economía boliviana. Revista de Análisis, La Paz, Vicepresidencia del Estado Plurinacional de Bolivia, n.3, 2008.

GARCÍA LINERA, Álvaro. El papel del Estado en el Modelo Nacional Productivo. Discursos y Ponencias del Vicepresidente del Estado Plurinacional de Bolivia. La Paz: Vicepresidencia del Estado Plurinacional de Bolivia, n.6, 2009a.

GARCÍA LINERA, Álvaro. La potencia plebeya. Acción colectiva e identidades indígenas, obreras y populares en Bolivia. Bogotá: Siglo del Hombre Editores y CLACSO, 200gb.

GARCÍA LINERA, Álvaro; GUTIÉRREZ, Raquel; PRADA, Raúl; TAPIA, Luis. El retorno de la Bolivia plebeya. La Paz: Comuna, 2000.

GARCÍA LINERA, Álvaro. Democratizaciones plebeyas. La Paz: Muela del Diablo Editores, 2002.

GAUDICHAUD, Franck; MODONESI, Massimo; WEBBER, Jeffrey. Los gobiernos progresistas Latinoamericanos del siglo XXI: ensayos de interpretación histórica. Ciudad de Mexico: Universidad Nacional Autónoma de México, 2019.

GRAPPI, Giorgio. Logistica. Roma: Ediesse, 2016.

GUTIERRÉZ AGUILAR, Raquel. Horizontes comunitario-populares. Madrid: Traficantes de sueños, 2017.

GUDYNAS, Eduardo. Estado compensador y nuevos extractivismos: Las ambivalencias del progresismo sudamericano. In: Nueva Sociedad, Buenos Aires, n. 237, enero-febrero 2012.

HALE, Charles R. Neoliberal Multiculturalism: The Remaking of Cultural Rights and Racial Dominance in Central America. In: PoLAR, v. 28, n. 1, 2005, p.10-28.

HALE, Charles R.; MILLAMAN, Rosamel. Cultural Agency and Political Struggle in the Era of Indio Permitido. In: Doris Sommer (coord.). Cultural Agency in the Americas, NC: Duke University Press, 2005, p. 281-314.

HARVEY, David. El nuevo imperialismo: Acumulación por desposesión. Socialist Register, 2004, disponible en: bibliotecavirtual.clacso.org.ar/ar/libros/social/harvey.pdf. Acceso el: $16 / 06 / 2020$.

HURTADO, Javier. El Katarismo. La Paz: Hisbol, 1986.

KAY, Cristóbal; VERGARA-CAMUS, Leandro (coord.) La cuestión agraria y los gobiernos de izquierda en América Latina: campesinos, agronegocio y neodesarrollismo. Buenos Aires: CLACSO, 2018.

KLEIN, S. Herbert. A Concise History of Bolivia: Second Edition. Cambridge: Cambridge University Press, 2011. 
LÓPEZ, Pabel; MAKARAN, Gaya. Recolonización en Bolivia. Neonacionalismo extractivista y resistencia comunitaria. Ciudad de México: Universidad Nacional Autónoma de México, 2018.

MAMANI RAMÍREZ, Pablo, Gobiernos barriales y su poder: Guerra del gas en El AltoBolivia. Sujetos y formas de la transformación política en Bolivia. México: Editorial Tercera Piel, 2006.

MCKAY, M. Ben. Extractivismo agrario. Dinámicas de poder, acumulación y exclusión en Bolivia. La Paz: Fundación Tierra, 2018.

MENENDEZ, Mariana. Entre mujeres: nuestro deseo de cambiarlo todo. Apantle, n. 3, p. 53$68,2017$.

MODONESI, Massimo. Revoluciones pasivas en América. Ciudad de México: Universidad Autónoma Metropolitana; Itaca, 2017.

MORELL I TORRA, Pere. Autonomía Guaraní Charagua lyambae. Una anàlisi etnogràfica dels processos d'implementació de l'autonomia indígena a l'Estat Plurinacional de Bolívia. Barcelona: Universitat de Barcelona, 2013.

OLIVERA, Oscar; LEWIS, Tom (coord.). ¡Cochabamba!: Water-War in Bolivia. Cambridge, MA.: South End Press, 2004.

PAZ, Sarela. La Marcha Indígena del Tipnis en Bolivia y su relación con los modelos extractivos de América Del Sur. Somos Sur Press, 2012a.

PAZ, Sarela. El Conflicto del Territorio Indígena Parque Nacional Isibóro Sécure (TIPNIS) y sus consecuencias para el Estado Plurinacional de Bolivia. En BAUTISTA, Rafael et al. (coord.). La victoria indígena del TIPNIS. La Paz: Autodeterminación, 2012b.

PETRAS, James; VELTMEYER, Henry (coord.). Social Movements and State Power Argentina, Brazil, Bolivia, Ecuador. London: Pluto Press, 2005.

POSTERO, Nancy G. Now We Are Citizens. Indigenous Politics in Postmulticultural Bolivia. Stanford: Stanford University Press, 2007.

POSTERO, Nancy G. The Indigenous State. Race, Politics, and Performance in Plurinational Bolivia. Oakland: University of California Press, 2017.

REINAGA, Fausto. La revolución india. La Paz: [s/d], 1970.

RICCIARDI, Maurizio. Dallo Stato moderno allo Stato globale. Storia e trasformazione di un concetto. In: SCIENZA \& POLITICA, v. 25, n. 48, p. 75-93, 2013.

RIVERA CUSICANQUI, Silvia. Pueblos originarios y estado. v. 2 de Gestión pública intercultural. La Paz: Azul Editores, 2008. 
RIVERA CUSICANOUI, Silvia. Mito y desarrollo en Bolivia. El giro colonial del gobierno del MAS. La Paz: Plural Ediciones, 2014.

RUDAN, Paola. "Bolívar's Discurso de Angostura" and the constitution of the people. Storicamente, n.10, p.1-12, 2014.

RUDAN, Paola. The Strike that Made a Difference. Critical Times, v.1, n.1, p. 241-262, 2018.

SAAVEDRA, José Luis. ¡Resistencia digna!: el TIPNIS entre la IX marcha IX indígena y la consulta espuria. La Paz: Autodeterminación, 2013.

SAAVEDRA, José Luis. Corrupción en el Fondo Indígena de Bolivia. Pukara, La Paz, año 9, n. $105,2015$.

SAAVEDRA, José Luis. ¡Resistencia digna! Violencias Gubernamentales y Luchas indígenas en el Tipnis y Takovo Mora. La Paz: Autodeterminación, 2019.

SALAZAR LOHMAN, Huáscar. Se han adueñado del proceso de lucha. Horizontes comunitario-populares en tensión y la reconstitución de la dominación en la Bolivia del MAS. Cochabamba: SOCEE; Autodeterminación, 2015.

SCHAVELZON, Salvador. El nacimiento del Estado Plurinacional de Bolivia. Etnografía de una Asamblea Constituyente. Bolivia: CLACSO; Plural; CEJIS; IGWIA, 2012

SAMADDAR, Ranabir. The Materiality of Politics: Volume 1. The Technologies of Rule. London: Anthem Press, 2007.

SPRONK, Susan. The Politics of Third World Water Privatisation: Neoliberal Reform and Popular Resistance in Cochabamba and El Alto, Bolivia. PhD Tesis, Toronto: York University, 2007.

SPRONK, Susan. Struggles Against Accumulation by Dispossession in Bolivia: The Political economy of Natural Resource Contention. Latin American Perspectives, v. 34, n. 2, p. 3147, 2007.

SVAMPA, Maristella. Consenso de los Commodities, Giro Ecoterritorial y Pensamiento crítico en América Latina. In: OSAL. Movimientos socioambientales en América Latina. Buenos Aires: CLACSO, p.15-38, 2012.

SVAMPA, Maristella. Del cambio de época al fin de ciclo: gobiernos progresistas, extractivismo, y movimientos sociales en América Latina. Buenos Aires: Edhasa, 2017.

STEFANONI, Pablo. El nacionalismo indígena en el poder. Observatorio Social de America Latina, v. 6, n.19, p. 37-44, 2006. 
TAPIA, Luis. La condición multisocietal. Multiculturalidad, pluralismo y modernidad. La Paz: Muela del diablo /CIDES-UMSA, 2002.

TAPIA, Luis. Política salvaje. La Paz: Clacso/Muela del Diablo / Comuna, 2008. TAPIA, Luis. Consideraciones sobre el estado plurinacional. In: Descolonización en Bolivia: cuatro ejes para comprender el cambio. La Paz: Vice-presidencia del Estado/Fundación Boliviana para la Democracia Multipartidaria, p. 135-168, 2011.

TAPIA, Luis. El leviatán criollo. La Paz: El Horizonte Interior, 2014. VILLEGAS, Pablo. Geopolítica de las carreteras y el saqueo de los Recursos Naturales. Cochabamba: CEDIB, 2013.

WEBBER, Jefferey R. Red October: Left-Indigenous Struggles in Modern Bolivia. LeidenBoston: Brill, 2011.

ZAVALETA MERCADO, René. Bolivia: Crecimiento de la idea nacional, La Habana: Casa de las Américas, 1967.

ZAVALETA MERCADO, René. Lo nacional popular en Bolivia, México, Siglo XXI, 1986.

\section{Detalles del autor}

Camilla De Ambroggi

Estudiante de Doctorado, Universidad de Bolonia (Italia), Departamento de Historia, Cultura y Civilizaciones (DiSCi). E-mail: camilla.deambroggi2@unibo.it 